\title{
Physicochemical Identity of $\alpha$-Ovomucins or $\beta$-Ovomucins Obtained from the Sonicated Insoluble and Soluble Ovomucins
}

\author{
Shigeru Hayakawa and Yasushi Sato \\ Laboratory of Food Science and Technology (Animal Product), Faculty of Agriculture, \\ Nagoya University, Chikusa, Nagoya, Japan \\ Received January 10, 1977
}

\begin{abstract}
The identity of $\alpha$-ovomucins obtained from the sonicated insoluble ovomucin ( $\mathrm{S} \alpha-\mathrm{OM}$ (I)) and soluble ovomucin ( $\mathrm{S} \alpha-\mathrm{OM}(\mathrm{S}))$ was demonstrated by carbohydrate and amino acid analyses, circular dichroism, ultracentrifugation and electrophoresis, and it was concluded that $\mathbf{S} \alpha-\mathrm{OM}$ (I) was the same component as $\mathbf{S} \alpha-\mathrm{OM}(\mathrm{S})$.

Physicochemical properties of $\beta$-ovomucins obtained from the two kinds of ovomucin ( $\mathrm{S} \beta-\mathrm{OM}(\mathrm{I}), \mathrm{S} \beta-\mathrm{OM}(\mathrm{S}))$ were compared with each other by the same methods as described above. $\mathbf{S} \beta$-OM (S) consisted of $\beta$-ovomucin and a small amount of $\alpha$-ovomucin bound with it, while $\mathbf{S} \beta$-OM (I) consisted of only $\beta$-ovomucin.

Since the insoluble ovomucin contained $\beta$-ovomucin two and a half times as much as the soluble ovomucin did, it was suggested that the difference in the content of $\beta$-ovomucin was mainly responsible for the differences in viscous property, molecular weight and solubility between the insoluble and the soluble ovomucins.
\end{abstract}

Egg white is composed of three phases, nner thin white, thick white and outer thin white. The thick white could be ultracentriugally separated into a gel fraction and a iquid fraction. ${ }^{1)}$ The liquid fraction of thick white was similar to thin white and the viscosity of the gel fraction was far higher than that of he liquid fraction or thin white. ${ }^{2)}$ The viscosty $^{3)}$ and molecular weight ${ }^{4,5)}$ of the insoluble womucin obtained from the gel fraction or whole thick white were also much higher than hose of the soluble ovomucin obtained from he liquid fraction or thin white.

It has been shown that ovomucin is comlosed of a carbohydrate poor component $\alpha$-ovomucin) and a carbohydrate rich comonent ( $\beta$-ovomucin $)^{1,5 \sim 7)}$ and that $\beta$-ovomucin ff the gel fraction is solubilized into the liquid action during natural thinning. ${ }^{1,8,9)} \beta$ vomucin of purified insoluble ovomucin was Iso solubilized into the ovalbumin solution $r$ the buffer solution of low ionic strength uring storage under an asceptic condition. ${ }^{10}$ ) In our previous paper, ${ }^{57}$ it was shown that le soluble ovomucin was dissociated into two components, $\alpha$-ovomucin and $\beta$-ovomucin, by sonication.

In the present studies, $\alpha$ - and $\beta$-ovomucins obtained from the insoluble ovomucin by sonication were compared with those obtained from the soluble ovomucin by sonication. The identity of $\alpha$-ovomucins or $\beta$-ovomucins obtained from the two kinds of ovomucin was examined in terms of some physicochemical properties.

\section{MATERIALS AND METHODS}

Preparation of the $\alpha$-ovomucin and the $\beta$-ovomucin. The insoluble ovomucin was prepared by the method of Kato et al., ${ }^{13}$ and the soluble ovomucin was prepared by the method described in our previous paper. ${ }^{5}$ ) Egg white was obtained from White Leghorn hens within $6 \mathrm{hr}$ after laying. Thick white was separated from thin white with a sieve and homogenized in a mechanical blender at a low enough speed to avoid foaming. The homogenized thick white was separated into gel and liquid fractions by ultracentrifugation at $59,000 \times g$ for $1 \mathrm{hr}$. The gel fraction was washed with $2 \% \mathrm{KCl}$ solution until the washing was free from protein, and subsequently with water, and suspended in Menzel buffer (pH 9.5, ionic strength 0.01). The gel- 
like precipitate obtained by the above procedure was designated as the insoluble ovomucin. On the other hand, the liquid fraction was diluted with a three-fold volume of water and adjusted to $\mathrm{pH} 6$ with $1 \mathrm{~N} \mathrm{HCl}$. The resulting precipitate was collected by decantation (without centrifugation) after standing overnight. The precipitate was washed with water twice and then dissolved in $0.1 \mathrm{~m}$ Menzel buffer, $\mathrm{pH}$ 9, containing $0.4 \mathrm{M} \mathrm{NaCl}$. About $30 \mathrm{ml}$ of the solution was applied to a Sepharose $4 \mathrm{~B}$ column $(2.5 \times 40 \mathrm{~cm})$ and eluted with the above buffer. Fractions eluted at the void volume were pooled. Ovomucin obtained by the above procedure was designated as the soluble ovomucin.

Both the insoluble and the soluble ovomucins were dialyzed against Menzel buffer ( $\mathrm{pH} 9.5, i=0.01$ ) for $24 \mathrm{hr}$ and subsequently sonicated for $10 \mathrm{~min}$ at $2^{\circ} \mathrm{C}$ under the conditions of $100 \mathrm{~W}$ and $9 \mathrm{kHz}$. The sonicated insoluble and soluble ovomucins were dialyzed against $0.01 \mathrm{M}$ Tris- $\mathrm{HCl}$ buffer, $\mathrm{pH} 8$, and applied to a DEAE-cellulose column. In this paper, the $\alpha$-ovomucins fractionated from the sonicated insoluble and soluble ovomucins by DEAE-cellulose column chromatography are abbreviated to $\mathrm{S} \alpha-\mathrm{OM}(\mathrm{I})$ and $\mathrm{S} \alpha-\mathrm{OM}(\mathrm{S})$, respectively, and the $\beta$-ovomucins fractionated from the sonicated insoluble and soluble ovomucins are abbreviated to $\mathrm{S} \beta-\mathrm{OM}(\mathrm{I})$ and $\mathrm{S} \beta-\mathrm{OM}(\mathbf{S})$, respectively.

DEAE-cellulose column chromatography. The sonicated insoluble and soluble ovomucins were applied to a DEAE-cellulose column $(2 \times 40 \mathrm{~cm})$ previously equilibrated with $0.01 \mathrm{~m}$ Tris- $\mathrm{HCl}$ buffer, $\mathrm{pH} 8$. Elution was carried out with $1000 \mathrm{ml}$ of a $0 \sim 0.5 \mathrm{M}$ linear gradient of $\mathrm{NaCl}$ in $0.01 \mathrm{M}$ Tris- $\mathrm{HCl}$ buffer, $\mathrm{pH} 8$. An elution pattern was drawn based on the hexose concentration which was determined by the phenol-sulfuric acid method. ${ }^{11)}$

Gel filtration. Gel filtration was performed on a Sepharose 4B column $(2.5 \times 40 \mathrm{~cm})$ equipped with a reverse flow adaptor. Elution was made with a $0.01 \mathrm{M}$ Tris-HCl buffer, $\mathrm{pH} 8$. Elution patterns were drawn based on the hexose concentration.

Circular dichroism. Circular dichroism (CD) measurement was carried out on a $\mathrm{J}-40 \mathrm{~A}$ spectropolarimeter (Japan Spectroscopic Co., Ltd.) with a $C D$ attachment. All measurements were made in a $0.1 \mathrm{~cm}$ cell and between 200 and $300 \mathrm{~nm}$ of wave length. Concentrations of the ovomucin solutions used were $0.4 \sim 1 \mathrm{mg} / \mathrm{ml}$ in $0.01 \mathrm{~m}$ Tris- $\mathrm{HCl}$ buffer, $\mathrm{pH} 8$.

Cellulose acetate electrophoresis. Cellulose acetate electrophoresis was carried out on a cellulose acetate strip (Separax, $6 \mathrm{~cm}$ long, purchased from Joko Sangyo Co., Ltd., Tokyo) at a constant voltage of $50 \mathrm{~V}$ for $2 \mathrm{hr}$. The buffer solution used contained $0.3 \mathrm{~m}$ boric acid and $0.075 \mathrm{M} \mathrm{NaOH}$ at $\mathrm{pH} 8.2$. The strips were stained either with $1 \%$ Ponceau $3 \mathrm{R}$ in $6 \%$ trichloroacetic acid ( $\alpha$-ovomucin) or with $0.5 \%$ Alcian Blue $8 \mathrm{GS}$ in $3 \%$ acetic acid ( $\beta$-ovomucin).

SDS polyacryiamide gel electrophoresis. SDS polyacrylamide gel electrophoresis was carried out on $5 \%$ polyacrylamide gel containing $0.1 \%$ SDS as described by Weber and Osborn. ${ }^{12)}$ The gels were stained either with $0.5 \%$ Amido Black $10 \mathrm{~B}$ in $15 \%$ acetic acid ( $\alpha$ ovomucin) or with periodic acid-Shiff reagent $(\beta$ ovomucin).

Sedimentation velocity experiment. Sedimentation velocity experiments were carried out with a Hitachi UCA $1 \mathrm{~A}$ ultracentrifuge at $60,000 \mathrm{rpm}$ and $20^{\circ} \mathrm{C}$ at various concentrations of ovomucin in $0.05 \mathrm{M}$ Tris$\mathrm{HCl}$ buffer ( $\mathrm{pH} 8$ ) containing $0.05 \mathrm{M} \mathrm{NaCl}$.

Carbohydrate analysis. Total hexose content was determined by the orcinol method ${ }^{13\rangle}$ with an equimolar mixture of galactose and mannose used as a standard. Galactose and mannose were determined by gas-liquid chromatography ${ }^{14}$ as described in the previous paper. ${ }^{5)}$ Total hexosamine content was determined by ElsonMorgan's method, as modified by Neuhaus and Letzring, ${ }^{15)}$ with glucosamine used as a standard. Galactosamine and glucosamine were determined with a JLC-5AH automatic amino acid analyser (Japan Electron Optics Laboratory) and calculated as $\mathrm{N}$-acetylhexosamine. Sialic acid content was determined by the thiobarbituric acid method ${ }^{16)}$ after hydrolysis of samples with $0.1 \mathrm{~N} \mathrm{H}_{2} \mathrm{SO}_{4}$ at $80^{\circ} \mathrm{C}$ for $1 \mathrm{hr}$ in sealed ampules. Ester sulfate was determined after hydrolysis with $6 \mathrm{~N} \mathrm{HCl}$ at $100^{\circ} \mathrm{C}$ for $9 \mathrm{hr}$ in sealed ampules by the method of Dodgson and Spencer. ${ }^{17)}$

Amino acid analysis. Dry samples $(4 \mathrm{mg})$ were hydrolysed at $110^{\circ} \mathrm{C}$ for $24 \mathrm{hr}$ with $6 \mathrm{~N} \mathrm{HCl}(2 \mathrm{ml})$ in sealed evacuated ampules. The hydrolysates were dried and dissolved in $0.01 \mathrm{~N} \mathrm{HCl}$. Amino acid analyses were carried out with a JLC-5AH automatic amino acid analyser.

\section{RESULTS}

Figure 1 shows the elution profiles in DEAE-cellulose column chromatography of the sonicated insoluble and soluble ovomucins. Both $\mathrm{S} \alpha-\mathrm{OM}(\mathrm{I})$ and $\mathrm{S} \alpha-\mathrm{OM}(\mathrm{S})$ were eluted in almost the same position. $\mathrm{S} \beta$-OM(I) was eluted in a slightly faster position than $S \beta$ OM(S). Relative content of $\alpha$ - and $\beta$-ovomucins was determined by triangulation of the peaks revised by the hexose content of $\mathrm{S} \alpha-\mathrm{OM}(\mathrm{I}) \quad(6.3 \%), \quad \mathrm{S} \beta-\mathrm{OM}(\mathrm{I}) \quad(20.1 \%), \quad \mathrm{S} \alpha-$ 


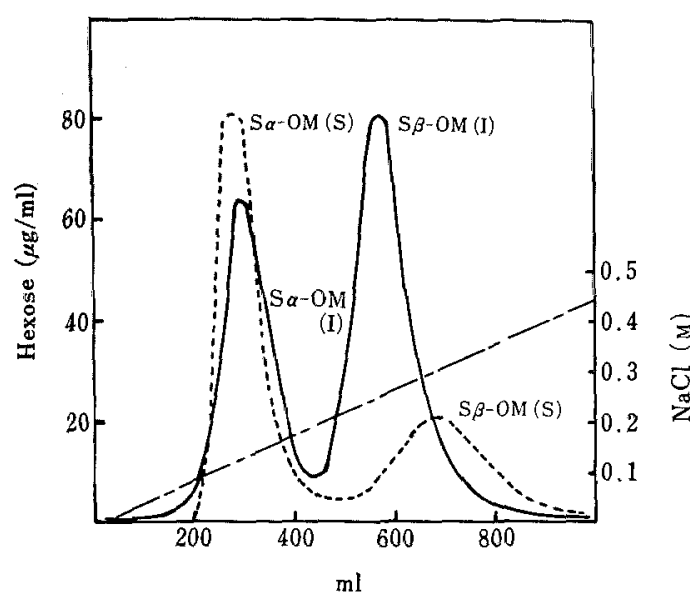

Fig. 1. DEAE-cellulose Column Chromatography of the Sonicated Insoluble and Soluble Ovomucins.

- the sonicated insoluble ovomucin; -..... the sonicated soluble ovomucin; - - -, NaCl concentration
$\mathrm{OM}(\mathrm{S})(6.3 \%)$ and $\mathrm{S} \beta-\mathrm{OM}(\mathrm{S})(19.8 \%)$. S $\alpha-$ $\mathrm{OM}(\mathrm{I})$ and $\mathrm{S} \beta-\mathrm{OM}(\mathrm{I})$ accounted for approximately $67 \%$ and $33 \%$ of the sonicated insoluble ovomucin, respectively. $\mathrm{S} \alpha-\mathrm{OM}(\mathrm{S})$ and $\mathrm{S} \beta$-OM(S) accounted for approximately $87 \%$ and $13 \%$ of the sonicated soluble ovomucin, respectively.

Carbohydrate compositions of $\mathrm{S} \alpha-\mathrm{OM}(\mathrm{I})$, $\mathrm{S} \alpha-\mathrm{OM}(\mathrm{S}), \mathrm{S} \beta-\mathrm{OM}(\mathrm{I})$ and $\mathrm{S} \beta-\mathrm{OM}(\mathrm{S})$ are given in Table I. Carbohydrate compositions of $\mathrm{S} \alpha-\mathrm{OM}(\mathrm{I})$ and $\mathrm{S} \alpha-\mathrm{OM}(\mathrm{S})$ were almost identical except for the sialic acid content. Carbohydrate compositions of $\mathrm{S} \beta-\mathrm{OM}(\mathrm{I})$ and $\mathrm{S} \beta$ $\mathrm{OM}(\mathrm{S})$ were also similar to each other.

Amino acid compositions of $\mathrm{S} \alpha-\mathrm{OM}(\mathrm{I}), \mathrm{S} \alpha-$ $\mathrm{OM}(\mathrm{S}), \mathrm{S} \beta-\mathrm{OM}(\mathrm{I})$ and $\mathrm{S} \beta-\mathrm{OM}(\mathrm{S})$ are given in Table II. The amino acid composition of $\mathrm{S} \alpha-\mathrm{OM}(\mathrm{I})$ was exactly the same as that of

Table I. Carbohydrate Composition of Sonicated $\alpha$ - AND $\beta$-Ovomucins Values are shown in $\%$ per dry matter.

\begin{tabular}{|c|c|c|c|c|}
\hline Component & $\mathrm{S} \alpha-\mathrm{OM}(\mathrm{I})$ & $\mathrm{S} \alpha-\mathrm{OM}(\mathrm{S})$ & $\mathrm{S} \beta-\mathrm{OM}(\mathrm{I})$ & $\mathrm{S} \beta-\mathrm{OM}(\mathrm{S})$ \\
\hline Hexose & 6.3 & 6.3 & 20.1 & 19.8 \\
\hline Galactose & 4.3 & 4.4 & 19.7 & 19.4 \\
\hline Mannose & 2.0 & 1.9 & 0.4 & 0.4 \\
\hline $\mathrm{N}$-Acetylhexosamine & 8.5 & 7.5 & 21.6 & 19.1 \\
\hline N-Acetylgalactosamine & 0 & 0 & 9.8 & 8.0 \\
\hline N-Acetylglucosamine & 8.5 & 7.5 & 11.8 & 11.1 \\
\hline Sialic acid & 0.7 & 0.3 & 15.3 & 12.6 \\
\hline Sulfate & 0.2 & 0.4 & 2.9 & 3.1 \\
\hline
\end{tabular}

Table II. Amino Acid Composition of SoniCated $\alpha$ - And $\beta$-Ovomucins Values are shown in moles per 100 moles of amino acid.

\begin{tabular}{lcccc} 
& S $\alpha-\mathrm{OM}(\mathrm{I})$ & $\mathrm{S} \alpha-\mathrm{OM}(\mathrm{S})$ & $\mathrm{S} \beta-\mathrm{OM}(\mathrm{I})$ & $\mathrm{S} \beta-\mathrm{OM}(\mathrm{S})$ \\
\hline Lysine & 5.8 & 5.6 & 3.0 & 5.7 \\
Histidine & 2.1 & 2.1 & 1.1 & 1.9 \\
Arginine & 2.6 & 2.7 & 1.1 & 2.4 \\
Aspartic acid & 10.6 & 10.4 & 2.6 & 4.8 \\
Threonine & 6.7 & 6.6 & 20.0 & 13.5 \\
Serine & 7.8 & 7.9 & 18.4 & 6.5 \\
Glutamic acid & 9.4 & 9.9 & 5.6 & 7.2 \\
Proline & 5.6 & 5.4 & 2.9 & 3.7 \\
Glycine & 7.7 & 7.4 & 6.0 & 5.2 \\
Alanine & 4.8 & 4.9 & 2.5 & 3.4 \\
Cystine (half) & 7.0 & 6.7 & 3.1 & 4.2 \\
Valine & 6.7 & 6.4 & 1.1 & 1.1 \\
Methionine & 1.7 & 1.7 & 7.2 & 8.6 \\
Isoleucine & 5.6 & 6.8 & 7.3 & 7.4 \\
Leucine & 7.2 & 6.8 & 6.1 & 5.1 \\
Tyrosine & 3.5 & 3.6 & 3.6 & 2.5 \\
Phenylalanine & 4.0 & 3.9 & & \\
\hline
\end{tabular}




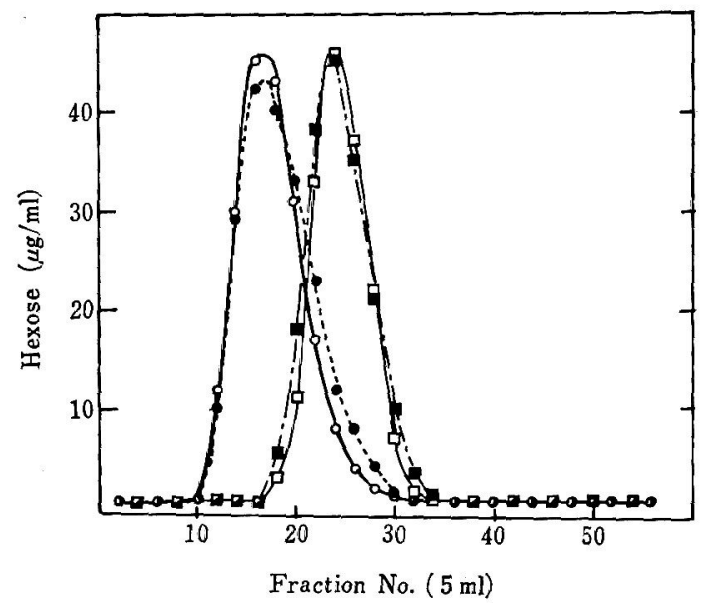

FIg. 2. Gel Filtration of the Sonicated $\alpha$ - and $\beta$ Ovomucins on a Sepharose 4B.

$$
\begin{aligned}
& \square-\square, \mathrm{S} \alpha-\mathrm{OM}(\mathrm{I}) ; \mathbf{-}-\mathrm{G} \alpha-\mathrm{OM}(\mathrm{S}) ; 0-0, \mathrm{~S} \beta-\mathrm{OM}(\mathrm{I}) \text {; } \\
& \square-\mathrm{S} \beta-\mathrm{OM}(\mathrm{S}) .
\end{aligned}
$$

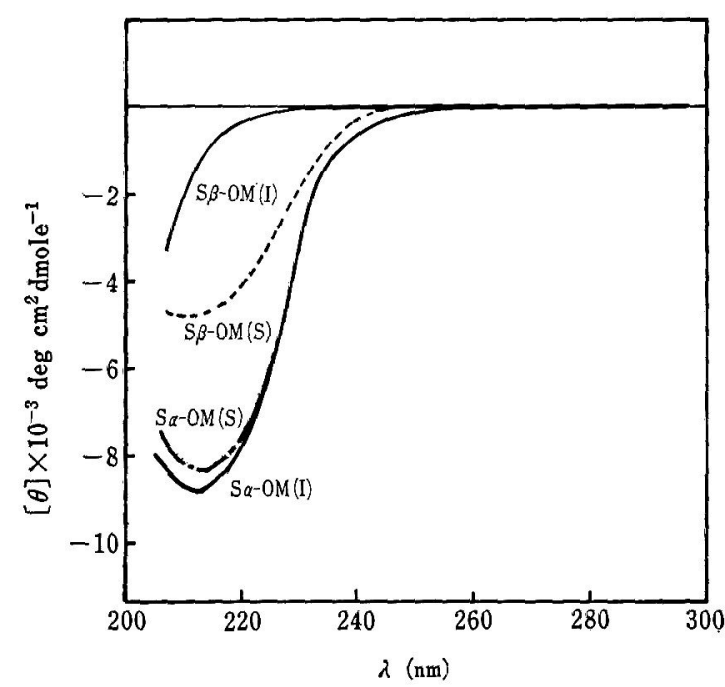

FIG. 3. Circular Dichroism Spectra of the Sonicated $\alpha$ - and $\beta$-Ovomucins.

$\mathrm{S} \alpha-\mathrm{OM}(\mathrm{S})$. However, $\mathrm{S} \beta$-OM(I) contained more threonine, serine and proline than $\mathrm{S} \beta$ $\mathrm{OM}(\mathrm{S})$, and $\mathrm{S} \beta-\mathrm{OM}(\mathrm{S})$ contained more acidic and basic amino acids than $\mathrm{S} \beta$-OM(I).

Figure 2 shows the elution patterns in gel filtration on a Sepharose 4B for different components of the sonicated ovomucins. $S \alpha-$ $\mathrm{OM}(\mathrm{I})$ and $\mathrm{S} \alpha-\mathrm{OM}(\mathrm{S})$ were eluted in the same position, and so were $\mathrm{S} \beta-\mathrm{OM}(\mathrm{I})$ and $\mathrm{S} \beta-\mathrm{OM}(\mathrm{S})$.

Figure 3 shows $C D$ spectra of $\mathrm{S} \alpha-\mathrm{OM}(\mathrm{I})$,

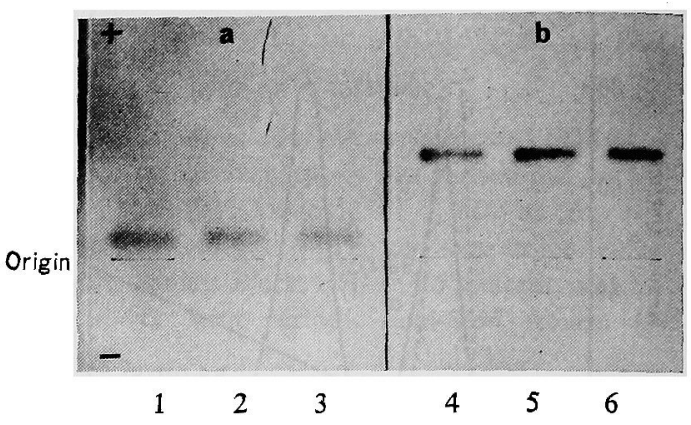

Frg. 4. Cellulose Acetate Electrophoresis of the Sonicated $\alpha$ - and $\beta$-Ovomucins.

The strips were stained with Ponceau (a) or Alcian Blue (b). From left to right (1) $\mathrm{S} \alpha-\mathrm{OM}(\mathbf{I})$, (2) $\mathrm{S} \alpha-$ $\mathrm{OM}(\mathrm{I})$ plus $\mathrm{S} \alpha-\mathrm{OM}(\mathrm{S})$, (3) S $\alpha-\mathrm{OM}(\mathrm{S})$, (4) $\mathrm{S} \beta-\mathrm{OM}(\mathrm{I})$, (5) $\mathbf{S} \beta$-OM(I) plus $\mathbf{S} \beta$-OM(S), (6) $\mathbf{S} \beta$-OM(S).

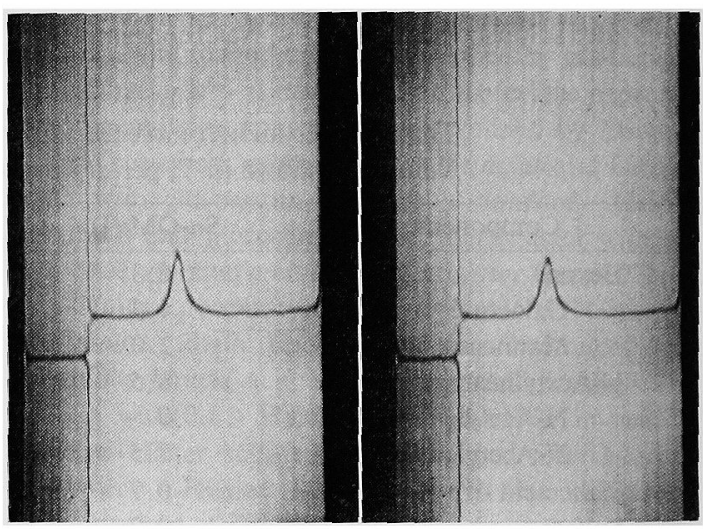

FIG. 5. Sedimentation-velocity Experiments with the Sonicated $\beta$-Ovomucins $(0.5 \% \mathrm{w} / \mathrm{v})$.

Frames were recorded after $60 \mathrm{~min}$ at $60,000 \mathrm{rpm}$. The temperature was $20^{\circ} \mathrm{C}$.

Left, $\mathbf{S} \beta-\mathrm{OM}(\mathrm{I})$; right, $\mathbf{S} \beta-\mathrm{OM}(\mathbf{S})$.

$\mathrm{S} \alpha-\mathrm{OM}(\mathrm{S}), \quad \mathrm{S} \beta-\mathrm{OM}(\mathrm{I})$ and $\mathrm{S} \beta-\mathrm{OM}(\mathrm{S}): \quad \mathrm{CD}$ spectrum of $S \alpha-O M(I)$ was very close to that of $\mathrm{S} \alpha-\mathrm{OM}(\mathrm{S})$. The spectra of $\mathrm{S} \alpha-\mathrm{OM}(\mathrm{I})$ and $\mathrm{S} \alpha-\mathrm{OM}(\mathrm{S})$ exhibited a feature attributable to a mixture of random coil and $\beta$-structure. ${ }^{18)}$ The spectrum of $\mathrm{S} \beta-\mathrm{OM}(\mathrm{I})$, which exhibited a feature attributable to random coil predominantly, ${ }^{18)}$ was different from that of $S \beta$ $\mathrm{OM}(\mathrm{S})$.

Figure 4 shows cellulose acetate electrophoretic patterns of $\mathrm{S} \alpha-\mathrm{OM}(\mathrm{I}), \mathrm{S} \alpha-\mathrm{OM}(\mathrm{S})$, $\mathrm{S} \beta-\mathrm{OM}(\mathrm{I}), \mathrm{S} \beta-\mathrm{OM}(\mathrm{S})$ and mixtures of the former two and of the latter two. The mixture of $\mathrm{S} \alpha-O M(\mathrm{I})$ and $\mathrm{S} \alpha-\mathrm{OM}(\mathrm{S})$ and that of $\mathrm{S} \beta$. 


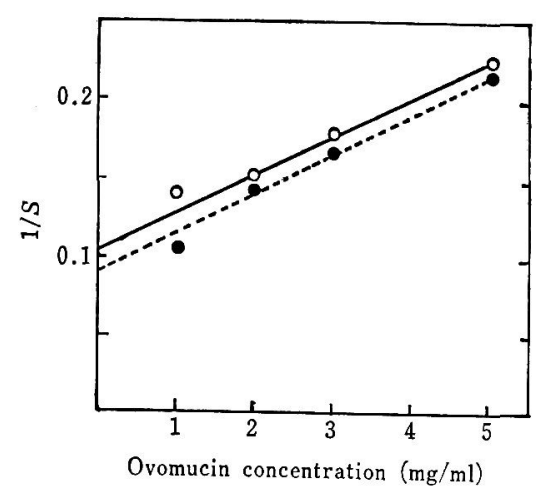

FIG. 6. Concentration-dependence of Sedimentation Coefficient of the Sonicated $\beta$-Ovomucins.

$\mathrm{O}-\mathrm{O}, \mathrm{S} \beta$-OM(I); ९---@, $\mathrm{S} \beta$-OM(S).

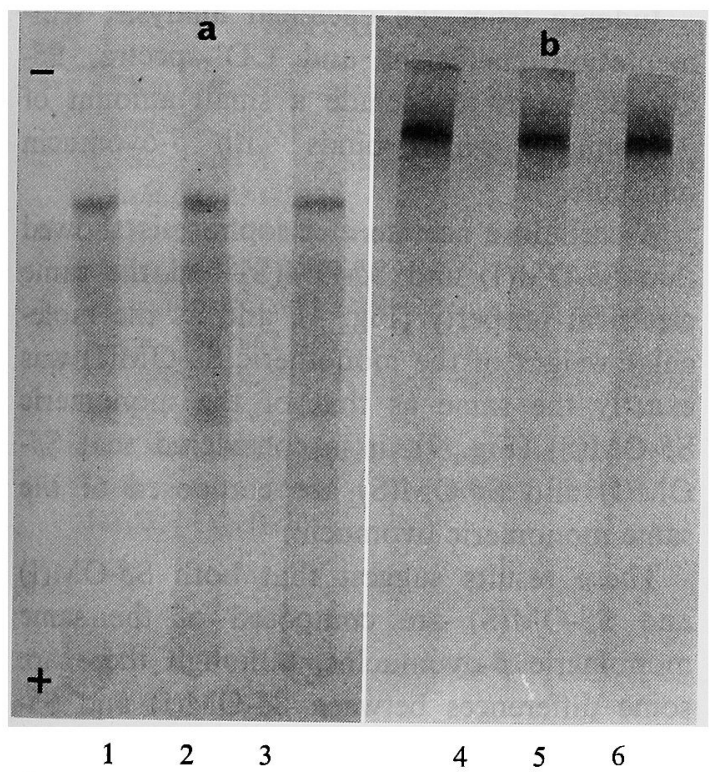

FIG. 7. Polyacrylamide Gel Electrophoresis in Sodium Dodecyl Sulfate (5\% acrylamide) of the Sonicated $\alpha$ - and $\beta$-Ovomucins. The gels were stained with Amido Black (a) or PAS (b).

From left to right (1) $\mathrm{S} \alpha-\mathrm{OM}(\mathrm{I})$, (2) $\mathrm{S} \alpha-\mathrm{OM}(\mathrm{I})$ plus $\mathrm{S} \alpha-O M(\mathrm{~S}),(3) \mathrm{S} \alpha-\mathrm{OM}(\mathrm{S})$, (4) $\mathrm{S} \beta-\mathrm{OM}(\mathrm{I})$, (5) $\mathrm{S} \beta-\mathrm{OM}(\mathrm{I})$ plus $\mathbf{S} \beta$-OM(S), (6) $\mathbf{S} \beta-\mathrm{OM}(\mathbf{S})$.

$\mathrm{OM}(\mathrm{I})$ and $\mathrm{S} \beta$-OM(S) migrated as a single band.

Figure 5 shows the sedimentation patterns of $\mathrm{S} \beta$-OM(I) and $\mathrm{S} \beta-\mathrm{OM}(\mathrm{S})$. Both $\mathrm{S} \beta-\mathrm{OM}(\mathrm{I})$ and $\mathrm{S} \beta$-OM(S) migrated as a single symmetrical peak. As $\mathrm{S} \alpha-\mathrm{OM}(\mathrm{I})$ and $\mathrm{S} \alpha-\mathrm{OM}(\mathrm{S})$ migrated as a broad and asymmetrical peak, their sedimentation coefficients could not be determined.
Figure 6 shows the concentration-dependence of the sedimentation coefficient of $\mathrm{S} \beta$ $\mathrm{OM}(\mathrm{I})$ and $\mathrm{S} \beta-\mathrm{OM}(\mathrm{S})$. High concentrationdependence was seen in $\mathrm{S} \beta$-OM(I) and $\mathrm{S} \beta$ $\mathrm{OM}(\mathrm{S})$. The sedimentation coefficient of $\mathrm{S} \beta$ $\mathrm{OM}(\mathrm{I})$ extrapolated to zero concentration was slightly smaller (9.7 S) than that of $\mathrm{S} \beta-\mathrm{OM}(\mathrm{S})$ (10.9 S).

Figure 7 shows the results of SDS polyacrylamide gel electrophoresis. The mixture of $\mathrm{S} \alpha-\mathrm{OM}(\mathrm{I})$ and $\mathrm{S} \alpha-\mathrm{OM}(\mathrm{S})$ moved as a single band, and likewise, that of $\mathrm{S} \beta-\mathrm{OM}(\mathrm{I})$ and $\mathrm{S} \beta$ $\mathrm{OM}(\mathrm{S})$ moved as a single band.

\section{DISCUSSION}

\section{$S \alpha-O M(I)$ and $S \alpha-O M(S)$}

Gel filtration, CD spectra and cellulose acetate electrophoresis indicated that $\mathrm{S} \alpha$ $\mathrm{OM}(\mathrm{I})$ and $\mathrm{S} \alpha-\mathrm{OM}(\mathrm{S})$ were the same in molecular weight distribution (Fig. 2), conformation (Fig. 3) and electrical property (Fig. 4). $\mathrm{CD}$ spectra of $\mathrm{S} \alpha-\mathrm{OM}(\mathrm{I})$ and $\mathrm{S} \alpha-\mathrm{OM}(\mathrm{S})$ were just the same as that of the unfractionated ovomucin prepared by Donovan et al., ${ }^{19)}$ suggesting that they were composed of about $70 \% \beta$-structure and $30 \%$ random coil, although it is not clear whether Donovan's ovomucin corresponds to the insoluble ovomucin, the soluble ovomucin or their mixture.

It was considered that the molecular weight of the monomeric $\mathrm{S} \alpha-\mathrm{OM}(\mathrm{I})$ was the same as that of the monomeric $\mathrm{S} \alpha-\mathrm{OM}(\mathrm{S})$ (Fig. 7).

Carbohydrate composition of $\mathrm{S} \alpha-\mathrm{OM}(\mathrm{I})$ was almost the same as that of $\mathrm{S} \alpha-\mathrm{OM}(\mathrm{S})$ except that the sialic acid content of $\mathrm{S} \alpha-\mathrm{OM}(\mathrm{I})$ was about twice as large as that of $\mathrm{S} \alpha-\mathrm{OM}(\mathrm{S})$ (Table I). In our previous studies, ${ }^{51}$ it was found that $4 \%$ of the total sialic acid of the soluble ovomucin was released by sonication, whereas no sialic acid was released from the insoluble ovomucin by sonication. Therefore, it seems that the lower content of sialic acid of $\mathrm{S} \alpha-\mathrm{OM}(\mathrm{S})$ resulted from the release of sialic acid by sonication.

Amino acid compositions of $\mathrm{S} \alpha-\mathrm{OM}(\mathrm{I})$ and $\mathrm{S} \alpha-\mathrm{OM}(\mathrm{S})$ were exactly the same (Table II).

From these results, it is concluded that 
$\mathrm{S} \alpha-\mathrm{OM}(\mathrm{I})$ and $\mathrm{S} \alpha-\mathrm{OM}(\mathrm{S})$ are the same glycoprotein molecules which are composed of the same monomeric ovomucins.

\section{$S \beta-O M(I)$ and $S \beta-O M(S)$}

It was found that there were some differences in amino acid composition between $\mathrm{S} \beta$ $\mathrm{OM}(\mathrm{I})$ and $\mathrm{S} \beta-\mathrm{OM}(\mathrm{S})$ (Table II), whereas the carbohydrate composition of $\mathrm{S} \beta$-OM(I) was quite similar to that of $\mathrm{S} \beta$-OM(S) (Table I). The slightly lower content of sialic acid in $\mathrm{S} \beta$-OM(S) is considered to be due to the release of sialic acid from it by sonication. $\mathrm{S} \beta$ $O M(I)$ contained more threonine, serine and proline $(47.3 \%)$ than $\mathrm{S} \beta-\mathrm{OM}(\mathrm{S})(35.9 \%$ ), and on the other hand, $\mathrm{S} \beta-\mathrm{OM}(\mathrm{I})$ contained less acidic and basic amino acids $(13.4 \%$ ) than $\mathrm{S} \beta$-OM(S) $(21.4 \%)$, Threonine, serine and proline of $\mathrm{S} \alpha-\mathrm{OM}(\mathrm{I})$ accounted for $22.9 \%$ of total amino acids, and acidic and basic amino acids accounted for $30.5 \%$. The protein moiety per dry weight of $\mathrm{S} \alpha-\mathrm{OM}(\mathrm{I})(74.6 \%)$, which was calculated from the sample weight and sum of each amino acid content, was about one-fourth of that of $\operatorname{S} \beta-O M(I)(17.1 \%)$. Therefore, even a small amount of $\alpha$-ovomucin which may be present in $\mathrm{S} \beta$-OM(S) must influence the amino acid composition of $S \beta$ $\mathrm{OM}(\mathrm{S})$. However, since $\mathrm{S} \beta$-OM(I) contained more carbohydrate $(60 \%)$ than $\mathrm{S} \alpha-\mathrm{OM}(\mathrm{I})$ $(15.7 \%)$, the inclusion of a small amount of $\alpha$-ovomucin has no effect on the carbohydrate composition of $\mathrm{S} \beta-\mathrm{OM}(\mathrm{S})$. Many mucous or sulfated glycoproteins contain very large amounts of threonine, serine and proline; namely those amino acids of bovine submaxillary gland glycoprotein ${ }^{20)}$ dog gastric mucosa glycoprotein, ${ }^{21)}$ rabbit small intestinal mucosa $^{22)}$ and chick allantoic fluid ${ }^{23)}$ account for $47 \%, 78 \%, 79 \%$ and $66 \%$, respectively. Therefore, it seems that $\mathrm{S} \beta-\mathrm{OM}(\mathrm{I})$ is more purified glycoprotein than $\mathrm{S} \beta$-OM(S).

$\mathrm{S} \beta$-OM(S) is composed of a mixture of random coil and $\beta$-structure whereas $\mathrm{S} \beta$-OM(I) mainly consists of random coil (Fig. 3). As $\mathrm{S} \alpha-\mathrm{OM}(\mathrm{I})$ or $\mathrm{S} \alpha-\mathrm{OM}(\mathrm{S})$ is considered to be composed of a mixture of random coil and $\beta$-structure, it is reasonable to presume that
$\mathrm{S} \beta-O M(S)$ contains a small amount of $\alpha$ ovomucin.

Sedimentation coefficient at a concentration of $0.5 \%$ was $4.4 \mathrm{~S}$ for $\mathrm{S} \beta-\mathrm{OM}(\mathrm{I})$ and $4.6 \mathrm{~S}$ for $\mathrm{S} \beta$-OM(S), while Robinson and Monsey showed that the sedimentation coefficient of the reduced $\beta$-ovomucin was $5.8 \mathrm{~S}$ at a concentration of $0.5 \%{ }^{7}$, As the sedimentation coefficients at $c=0\left(\mathrm{~s}_{0}\right)$ of $\mathrm{S} \beta-\mathrm{OM}(\mathrm{I})$ and $\mathrm{S} \beta$ $\mathrm{OM}(\mathrm{S})$ were $9.7 \mathrm{~S}$ and $10.9 \mathrm{~S}$, respectively (Fig. 6), it is considered that $\mathrm{S} \beta$-OM(S) molecule is slightly larger than $\mathrm{S} \beta-\mathrm{OM}(\mathrm{I})$. Broad peaks shown in the elution profiles of $S \beta$ $\mathrm{OM}(\mathrm{I})$ and $\mathrm{S} \beta$-OM(S) (Fig. 2) do not reflect their slight difference in molecular weight.

Judging from the chemical analysis, sedimentation coefficient and $\mathrm{CD}$ spectra, $\mathrm{S} \beta$ $\mathrm{OM}(\mathrm{S})$ seems to include a small amount of $\alpha$-ovomucin which binds with $\beta$-ovomucin molecule.

As cellulose acetate electrophoresis showed that $\mathrm{S} \beta-\mathrm{OM}(\mathrm{I})$ and $\mathrm{S} \beta-\mathrm{OM}(\mathrm{S})$ had the same electrical property (Fig. 4), and as the molecular weight of the monomeric $\mathrm{S} \beta-\mathrm{OM}(\mathrm{I})$ was exactly the same as that of the monomeric $\mathrm{S} \beta-\mathrm{OM}(\mathrm{S})$ (Fig. 7), it is considered that $\mathbf{S} \beta$ $\mathrm{OM}(\mathrm{I})$ and $\mathrm{S} \beta$-OM(S) are composed of the same monomeric ovomucin.

These results suggest that both $\mathrm{S} \beta$-OM(I) and $\mathrm{S} \beta-\mathrm{OM}(\mathrm{S})$ are composed of the same monomeric $\beta$-ovomucins, although there are some differences between $\mathrm{S} \beta$-OM(I) and $\mathbf{S} \beta$ $\mathrm{OM}(\mathrm{S})$ resulting from probable inclusion of a small amount of $\beta$-ovomucin in $S \beta-O M(S)$,

The insoluble ovomucin and the soluble ovomucin

Sato and Hayakawa ${ }^{2}$ showed that the viscosity of the gel (containing both the insoluble and soluble ovomucins) fraction ( $>$ 1200 c.p.) was much higher than that of the liquid fraction (3.8 c.p.) (containing only the soluble ovomucin). Kato et al. ${ }^{3)}$ also showed that the intrinsic viscosity of alkaline solution of the insoluble ovomucin $(2.6 \mathrm{dl} / \mathrm{g})$ obtained from whole thick white was higher than that of the soluble ovomucin $(1.3 \mathrm{dl} / \mathrm{g})$ obtained from thin white. The molecular weight of 
Donovan's ovomucin $\left(40 \sim 240 \times 10^{6}\right)^{4)}$ was much higher than that of the soluble ovomucin $\left(8.3 \times 10^{6}\right)$. $^{5} \quad$ Inclusion of a slight amount of $\alpha$-ovomucin in $S \beta$-OM(S) is not responsible for the differences in viscous property, molecular weight and solubility between the insoluble and the soluble ovomucins. Rather, the difference in the content of $\beta$-ovomucin between the two kinds of ovomucin is mainly responsible for the differences in their properties. The content of $\mathrm{S} \beta-\mathrm{OM}(\mathrm{I})(34 \%)$ in the insoluble ovomucin was about two and a half times as much as that of $\operatorname{S\beta -OM}(\mathrm{S})(13 \%)$ in the soluble ovomucin.

\section{REFERENCES}

1) A. Kato, R. Nakamura and Y. Sato, Agric. Biol. Chem., 35, 351 (1971).

2) Y. Sato and S. Hayakawa, Nippon Nôgeikagaku Kaishi, 51, 47 (1977).

3) A. Kato, R. Nakamura and Y. Sato, Agric. Biol. Chem., 34, 854 (1970).

4) Y. Tomimatsu and J. W. Donovan, J. Agr. Food. Chem., 20, 1067 (1972).

5) S. Hayakawa and Y. Sato, Agric. Biol. Chem., 40, 2397 (1976).

6) A. Kato and Y. Sato, ibid., 35, 439 (1971).

7) D. S. Robinson and J. B. Monsey, Biochem. J., 121, 537 (1971).
8) A. Kato and Y. Sato, Agric. Biol. Chem., 36, 831 (1972).

9) D. S. Robinson and J. B. Monsey, J. Sci. Food Agr., 23, 29 (1972).

10) Y. Sato, S. Hayakawa and R. Nakamura, $J$. Agr. Food Chem., 24, 798 (1976).

11) M. Dubois, K. A. Gilles, J. K. Hamilton and F. Smith, Anal. Chem., 28, 350 (1956).

12) K. Weber and M. Osborn, J. Biol. Chem., 244, 4406 (1969).

13) C. Francois, R. D. Marshall and A. Neuberger, Biochem. J., 83, 335 (1962).

14) C. C. Sweeley, R. Bentley, M. Makita and W. W. Wells, J. Am. Chem. Soc., 85, 2497 (1963).

15) O.W. Neuhaus and M. Letzring, Anal. Chem., 29, 1230 (1957).

16) L. Warren, J. Biol. Chem., 234, 1971 (1959).

17) K. S. Dodgson and B. Spencer, Biochem. J., 55, 436 (1953).

18) Y.H. Chen, J. T. Yang and K.H. Chau, Biochemistry, 13, 3350 (1974).

19) J. W. Donovan, J. G. Davis and L. M. White, Biochim. Biophys. Acta, 207, 190 (1970).

20) G. Tettamanti and W. Pigman, Arch. Biochem. Biophys., 124, 41 (1968).

21) T. Pamer, G. B. J. Glass and M.I. Horowitz, Biochemistry, 7, 3821 (1968).

22) T. Nemoto and Z. Yoshizawa, Biochim. Biophys. Acta, 192, 37 (1969).

23) K. Meyer, V. P. Bhavanandan, D. Yung, L. T. Lee and C. Howe, Proc. Natl. Acad. Sci. US, 58, 1655 (1967). 